\title{
SAÚDE DA FAMÍLIA NA PÓS-GRADUAÇÃO: UM COMPROMISSO ÉTICO INTERDISCIPLINAR NA PÓS-MODERNIDADE
}

\author{
Rosane Gonçalves Nitschke' \\ Ingrid Elsen ${ }^{2}$
}

\section{COMEÇANDO A REFLETIR SOBRE A QUESTÃO}

Desde meados dos anos 80 , a temática Saúde da Família tem sido foco de nossa atenção seja na assistência, ensino ou na pesquisa, traduzindo-se pela produção crescente de teses de doutorado, dissertações de mestrado, trabalhos de conclusão de curso de graduação e monografias de especialização, artigos em periódicos, seja como fruto de uma prática assistencial, ou de execução de projetos de extensão junto à família onde ela se encontre: instituições de saúde, comunidade, no seu domicílio, entre outros. Deste modo, percebese que, nestas duas décadas, a questão Saúde da Família tem se desenvolvido tanto na graduação, como na Pós-graduação de Enfermagem, sendo neste último nível de modo mais expressivo.

Uma década mais tarde, mais precisamente

Apesar de alguns autores se voltarem exclusivamente para dentro da familia para falar de saúde da família e família saudável, a prática tem nos mostrado que trabalhar com familia é estar em trânsito entre o micro e o macrosocial, entre o ser humano na sua individualidade e na sua coletividade, enfim é mergulhar infinitamente nas relações intra e extra-familiais. É aprender a relativizar! E a Pós-Graduação precisa garantir isto! em 1994, a partir do denominado Ano Internacional da Família, o tema Saúde da Família tem estado mais presente no nosso dia-a-dia, na medida que os órgãos governamentais o colocaram inicialmente como programa e, mais recentemente, como uma estratégia para reorientação do modelo assistencial (MINISTÉRIO DA SAÚDE, 1998), sendo proposta sua integração tanto a nível de graduação, como de Pós-graduação, com indicações de cursos de especialização, residência, bem como mestrado e doutorado.

Frente a esta situação e desenvolvendo atividades na Pós-graduação, ora como estudante, ora como docentes, passamos a nos perguntar: afinal, por quê pensar saúde da família na pós-graduação? Assim, delineamos nosso objetivo aqui: despertar uma reflexão sobre saúde da família no âmbito da pós-graduação.

Alguns autores (Gillis et al. 1989) já colocaram que, enquanto a graduação prepara profissionais para cuidar de famílias, a pós-graduação assume o papel de oferecer formação para terapia com famílias, no que se refere à especialização. Já a nível de mestrado e doutorado, a pós-graduação assume o desenvolvimento do conhecimento, destacando-se, entre outras questões, as conceituais, éticas, a partir de pesquisas. Para provocar o debate, colocamos que a importância da temática saúde da família na pós-graduação reside na questão de ser um compromisso ético dos profissionais da saúde, bem como das universidades e órgãos governamentais frente à

1 Enfermeira, Doutora em Filosofia de Enfermagem pela UFSC-SORBONNE, Professora Adjunto do Departamento de Enfermagem da UFSC, Coordenadora do Núcleo de Pesquisa e Estudos sobre o Quotidiano e Saúde de Santa Catarina (NUPEQS-SC) e do Projeto de Extensão NINHO: criando um espaço para assistir transdisciplinarmente a família; membro do Grupo de Assistência, Pesquisa e Educação em Saúde da Familia (GAPEFAM).

2 Doutora em Enfermagem pela Universidade da Califórnia ; Professora do Programa de Pós-Gradução em Enfermagem da UFSC; Coordenadora do Grupo de Assistência, Pesquisa e Educação em Saúde da Familia (GAPEFAM). 
população. Entretanto, antes é preciso refletir sobre a noção de saúde da família ou saúde familial ${ }^{3}$ bem como sua relação com família saudável.

\section{SAÚDE DA FAMÍLIA: UMA NOÇÃO EM QUESTÃO}

Se a compreensão da família passa por diferentes olhares, a saúde da família também pode acolher diferentes definições, dependendo da visão de mundo de cada um.

De acordo com Bomar (1990), embora exista dificuldade desenvolver uma noção de saúde da família, muitas definições envolvem diferentes dimensões podendo ser tanto biológicas, psicológicas e sociológicas como espirituais, dentro de um contexto cultural no qual a família interage, ao experenciar bem-estar ou doença, destacando que saúde da família é mais do que a ausência de doença.

Assim como há a saúde de indivíduos, também podemos falar em saúde da família e família saudável, conforme já se destacou em trabalhos anteriores (Nitschke, 1991 e Nitschke, 1995). Deste modo, segundo Gillis (1989), apesar de os indivíduos (membros participantes e componentes da família) serem interativos, a saúde desses indivíduos distingue-se da saúde da família.

Entretanto, se esta diferença é melhor acentuada entre a saúde do indivíduo e saúde da família, o mesmo já não se percebe quando os autores tratam de saúde da família e família saudável. Conforme Bomar (1990), as definições de saúde da família e família saudável derivam-se de uma variedade de marcos conceituais e teóricos.

Gillis (1989), citando o trabalho de Bawrnhill, também aborda as dimensões da saúde da família, referindo que são organizadas em quatro áreas: identidade de processos; mudanças; processamento de informação e estruturação de papéis.

Os terapeutas familiares definem a família saudável como aquela que é livre de psicopatologias e que tem um ótimo funcionamento familiar. Portanto, considera-se como saudável a família que tem um equilíbrio de coesão, flexibilidade e uma comunicação funcional.

Por sua vez, os teoristas desenvolvimentistas, estabeleceram que as famílias são saudáveis quando estão cumprindo tarefas de desenvolvimento no tempo apropriado. Ainda, segundo Bomar (1990), a família saudável pode ser aquela que possui como característica a habilidade para enfrentar o stress.

Conforme Bomar (1990), numa pesquisa realizada com 551 profissionais que trabalham com famílias, Curran observou que as características mais citadas de uma família saudável são: os membros comunicam-se (escutam um ao outro), e dão suporte um ao outro; há o ensinamento de respeito de um pelo outro; desenvolve o senso de unidade; possui senso de humor e para brincar; exibe um senso de responsabilidades partilhadas; ensina um senso de certo e errado; possui um forte senso de família rico em rituais e tradições; existe um equilíbrio de interação entre os membros; possui um centro religioso; há o respeito pela privacidade do outro; existem valores de ajudar o outro; cria um tempo para família à mesa para conversar; partilha tempo de lazer; e admite solicitar ajuda quando está com problemas.

Dentro da perspectiva interacionista, segundo Delaney (1986), família saudável é aquela que possui canais abertos de comunicação, regras flexíveis, auto-valorização elevada, e negociações bem sucedidas com elementos externos à família.

Pratt (1989), segundo Gillis, caracteriza a família saudável examinando seus laços com a comunidade, a interação entre os membros da família, a estrutura de papéis, a liberdade e as responsabilidades. Estas duas últimas autoras chamam nossa atenção para o aspecto de que quando a saúde envolve família, não é possível, limitá-la às suas interações internas, sendo essencial enfocar suas relações com o campo exterior, como seu ambiente, sua comunidade.

Para aquecer a reflexão, podemos resgatar a discussão, já levantada em tese (Nitschke, 1999), quanto à saúde e saudável, retomando o conceito proposto na VIII Conferência Nacional de Saúde ${ }^{4}$, ocorrida em 1986, tornando-se base ao sistema de saúde vigente. Deste modo, podemos dizer que os profissionais que trabalham na saúde da família, tem a finalidade de contribuir para se ter o que nasce e se origina das " das condições de alimentação, habitação, educação, renda, meio ambiente, trabalho, transporte, emprego, lazer, liberdade, acesso à posse de terra e acesso a serviços de saúde. E, 
assim, antes de tudo, o resultado das formas de organização social de produção, as quais podem

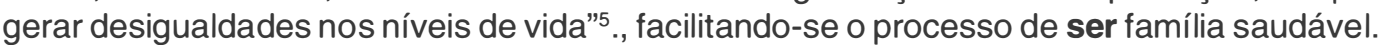

Penna (1996) ${ }^{6}$ levantou a discussão sobre os aspectos resultantes e resultados trazidos pela VIII Conferência Nacional de Saúde. Entretanto, se entendermos resultante, como o que emerge do verbo resultar ${ }^{7}$, como algo nascente, proeminente, original, tornar-se e, não como uma conseqüência lógica, acredita-se que existe uma relação entre as condições para ser família saudável e as condições para ter saúde. Todavia, ser família saudável, exige algo mais: as nuanças do ser-estar junto com.

Retomando algumas famílias, é possível concordar com $P e n n a^{8}$ quando diz que "saúde é do ter, saudável do ser... para ter saúde é preciso adquirir; para ser saudável, é preciso sentir »⿳9. Entretanto, as famílias não vêm o ser saudável como qualidade de saúde, como Meleis (1992), já que colocam a saúde como componente do seu ser saudável. Para elas, é preciso sentir-se bem, mas também ter... Vê-se que enfocar a saúde da família é mergulhar num mar de diversidades, no que se refere à sua compreensão, mas é sobretudo, mergulhar na sua rede de interações, tanto intra quanto extra-familiais, o que vale dizer trazer à tona suas necessidades, suas potencialidades, suas forças, traçando sua rede e suporte social, envolvendo a sua comunidade, seu ambiente, seu território, seu planeta, situandoa num tempo e num espaço, enfim, contextualizando-a.

\section{SAÚDE DA FAMÍLIA NA PÓS-GRADUAÇÃO: UMA QUESTÃO DE COMPROMISSO ÉTICO}

Dentro do nosso entendimento, um dos papéis da Pós-Graduação tem sido o de capacitar profissionais, comprometidos eticamente, para a produção, desenvolvimento e divulgação do conhecimento, em nível avançado, que subsidie a prática, o ensino e a pesquisa na área da saúde.

Mas o que é estar comprometido eticamente?

Para nos aproximar de nossa compreensão, podemos resgatar Savater(1994), quando afirma que a primeira exigência ética é a de construir uma boa existência, uma boa vida humana que, para ser tal, só poderá ser vivida entre outros seres humanos. Assim, temos entendido ética como aquele "compromisso social, profissional e científico que o pesquisador tem com a melhoria da qualidade de vida da população" (Elsen; Nitschke, 1994, p.9)

Em outros trabalhos (Caponi; Elsen; Nitschke; 1995, Nitschke,1999), destacamos algumas dimensões do compromisso ético como: estar em sintonia com as necessidades, avanços, problemas, enfim a realidade das pessoas, dos grupos, da comunidade, da nação e do mundo; buscar respostas aos problemas e desejos, ou seja, criar, desenvolver e organizar conhecimentos e tecnologias para promover a melhoria da qualidade de vida e saúde; socializar conhecimento, ou seja, compartilhar saberes com as pessoas, os grupos, a comunidade e a nação; formar profissionais capazes de exercer uma profissão sem riscos para o outro; oferecer oportunidades para o desenvolvimento integral do ser humano, comprometido consigo próprio e com a comunidade. Destas, ressaltaremos três, para nos guiar em nossa reflexão.

\section{CAINDO NA REAL E ENCONTRANDO FAMÍLIAS NA PÓS-MODERNIDADE}

A primeira dimensão, estar em sintonia com as necessidades e avanços, problemas, enfim com a realidade das pessoas, dos grupos, da comunidade, da nação e do mundo, faz-nos ancorar numa perspectiva contextual e nos questionar: que tempo é este que vivenciamos? como estão as famílias nesta contemporaneidade?

Vivemos num contexto de diversidade, relatividade e de pluralidade de valores, que pode ser apresentado, segundo Hartman ${ }^{10}$, como Pós-modernidade.

Falar em Pós-modernidade é mergulhar num mundo de controvérsias, sendo ela foco de inúmeros e férteis debates por diversos estudiosos como Lyotard $^{11}$, Vatimo ${ }^{12}$, Coelho ${ }^{13}$, Maffesoli ${ }^{14}$, Santos ${ }^{15}$. Há autores que a negam em sua essência, outros que preferem não utilizar o termo, mas criam outra nomenclatura para falar de determinados traços destes outros tempos que estamos vivendo.

Todavia, como destaca Watier ${ }^{16}$, o importante encontra-se no conteúdo, nos elementos de compreensão e de descrição deste período atual que aí está, de tal modo que nos permita apreender 
alguma coisa sobre as experiências e interações sociais dos indivíduos, a relação com as instituições, bem como com as significações imaginárias que estas produzem, podendo inclusive guiá-los. Está claro que estamos passando para outros modos de organização soçial, mesmo que em algumas situações estas encontram-se apenas esboçadas.

Concordando, com este posicionamento é que trazemos a pós-modernidade, não só como pano de fundo, mas como expressão de todo um movimento que se vivencia ao longo de nossa história.

Num artigo sobre arte, segundo Vaistman ${ }^{17}$, Dilnot expõe o pós-moderno como um processo de interligação de fronteiras entre tipos de práticas que convencionalmente são considerados como inteiramente diferentes. Também neste sentido de convivência de coisas percebidas como diferentes, o pós-moderno é considerado como um dominante cultural: uma concepção que permite a presença e a coexistência de um espectro de características muito diferentes, ainda que interdependentes. Assim, a inexistência de um padrão dominante, não importa a que campo social se esteja referindo, é um primeiro traço que nos remete às tendências pós-modernas.

Com a saturação da modernidade, "o doméstico ou cotidiano" ressurgem, para Maffesoli". Temos agora a lógica do doméstico, quer dizer, recentramento no mais próximo, trazendo a idéia de 'proxemia', ou seja, a ênfase na relação com o meio ambiente, e com o outro social».

De acordo com Silva, ${ }^{19}$ a pós-modernidade é a supremacia da socialidade, a solidariedade de base, sobre a sociabilidade, a solidariedade mecânica, reportando-nos ao sentido maffesoliano do termo ${ }^{20}$. Deste modo, para Silva ${ }^{21}$, no caso da passagem do moderno ao pós-moderno, percebe-se que «não é o sistema econômico que muda radicalmente, mas a maneira de os indivíduos e grupos sociais relacionarem-se com ele».

A tecnologia tem encolhido o mundo físico, expandido e feito complexa a experiência cultural e social mundiais do indivíduo. Os indivíduos estão pessoalmente conectados com significativamente mais gente e variadas formas de vida esticam-se sobre o largo espaço geográfico. Nesta multiplicidade de relações, oferece-se uma excitante, mas assustadora mistura de visões, crenças e realidades mundiais. ${ }^{22}$

"Ligar o rádio, assistir um filme, abrir um jornal, receber um fax, corresponder-se pelo E-mail, ou assistir um jornal às altas horas da noite é tornar-se imerso no 'outro'23. Nós entendemos as opiniões, valores, medos, dúvidas, necessidades, aspirações e personalidades de estrelas de cinemas, sobreviventes de campos de concentração, atletas campeões, africanos vítimas a fome, vencedores do Prêmio Nobel, ativistas da AIDS, autores feministas... Escutamos, empatizamos, e absorvemos: ganhamos o potencial para entender opiniões, apreciando as possibilidades e experenciando os sentimentos de milhares de pessoas de cuja existência, raramente poderíamos imaginar. Em efeito, tornamo-nos habitados por outros, e adquirimos uma infinidade de fragmentários e freqüentemente competitivos selfs. ${ }^{24}$

É a tecnosocialidade da qual Maffesoli nos fala. Para ele, pode-se pensar num primeiro momento que a técnica é alguma coisa que tende ao isolamento, mas vê-se um processo inverso, atuando como um laço social, manifestando um "religare; uma re-aliança". ${ }^{25}$

Retomando-se a questão da globalização, que já vem surgindo desde a modernidade, segundo Silva ${ }^{26}$, ela agora significa mais a interdependência. "No campo da cultura, atrelado ao econômico, mas com suficiente margem de autonomia, tudo se interliga e se influencia, o que não quer dizer necessariamente homogeneização. Ao contrário, o local conserva-se, a diferença convive, o particular articula-se ao universal. Mesmo dentro de uma região, a diversidade é regra. A internacionalização do cotidiano não impede o florescimento da particularidade". A realidade é outra: o microscópico relativizou o macroscópico.

Na pós-modernidade o rigor fracassa. As regras não cessam de multiplicarem-se. Mas cada grupo pode estabelecer o seu contrato. Fundam-se éticas do instante. Entre a ortodoxia do dever-ser moderno e o supermercado ético pós-moderno, como refere Silva ${ }^{27}$, a distância é quilométrica.

Conforme Maffesoli ${ }^{28}$, existe indícios de que os grandes valores da modernidade chegaram a sua saturação, sendo que um deles está no fato de que na vida cotidiana «não há mais aquela crença exacerbada no futuro». Assim, para este autor, junto com o «simbolismo», o «interesse no presente» 
é o outro elemento mais importante da pós-modernidade ${ }^{29}$. Vive-se, deste modo, o que se pode chamar de presenteísmo.

E a realidade brasileira? Segundo Maffesolß30, o "gênero pós-moderno congrega elementos de vários estilos, com nuanças particulares, de acordo com a cor local de diversos países. Sua hipótese é de que há países como, por exemplo, o Brasil, que podem ter saltado sobre a modernidade. Deste modo, refere-se à carta de Marx a Vera Zassoulitch, onde ele considera favoravelmente a possibilidade de um país saltar etapas".

Conforme Maffesoli, algumas linhas da pós-modernidade são perfeitamente discerníveis no Brasil, tais como: o ecletismo (o pós-modernismo é plural, não é unidimensional); a integração da natureza na cultura e vice-versa; o patchwork, isto é, a construção de alguma coisa nova a partir de elementos diversos; a predominância da 'ética da estética', entendendo-se estética em sentido de percepção, sensação, emoção, etc. Ë deste modo que começamos a não nos surpreender com a colocação de que nosso país, mesmo com suas estatísticas chocantes de miserabilidade, vive a Pósmodernidade.

Silva ${ }^{31}$ também provoca inicialmente: «seria mesmo legítimo referir-se à pós-modernidade no Terceiro Mundo?», para posteriormente argumentar «a população primeiro-mundista foi arrastada para a intimidade com a terceiro-mundista, ainda que escandalosos graus de desigualdade persistam". Assim, o Brasil insere-se no desigual e articulado universo da internacionalização pós-moderna.

Barreto $^{32}$ reforça esta posição quando se refere à imagem da sociedade brasileira sendo "constituída de pluralismos, de contradições onde coabitam o arcaico e o moderno, a miséria absoluta e a opulência ostensiva. Não se trata de uma sociedade harmônica nem homogênea. Se pudermos falar em totalidade, trata-se muito mais de uma totalidade conflitual feita de confrontos e afrontamentos".

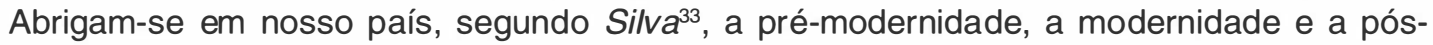
modernidade. Nosso país vivencia o sincretismo, a conjugação dos opostos, o casamento dos inconciliáveis à primeira vista. Tudo isto mostrando-se no tráfico de influências, na miséria, no analfabetismo, na violência selvagem e na indiferença, enfim nos aspectos relacionais da sociedade, onde "as amizades, as ligações grupais e as éticas locais valem mais do que as normas universais e a lei». Sem dúvida, "estamos dentro de um outro tipo de espaço simbólico diferente daquele das sociedades tradicionais e com outro tipo de sujeito social', parafraseando Akoun. Assim, perguntamonos: como iremos encontrar a família nestes tempos pós-modernos?

O predomínio da considerada família ideal da modernidade, segundo Vaitsman $^{34}$, vem desaparecendo. Ou seja, a chamada família tradicional, ou conjugal, como aquela formada pelo homem/ pai provedor financeiro e a mulher/mãe dona-de-casa, unidos pelo casamento (legal e indissolúvel), e seus filhos, vivendo sob o mesmo teto, passa a coexistir, cada vez mais, com uma rede de interações que incluem outros "conteúdos», chegando até a se institucionalizar sob novas formas.

Pode-se dizer que a família brasileira vem se traduzindo há muito tempo em famílias brasileiras, como afirmou Kaloustian ${ }^{35}$, não só pelos seus matizes étnico-culturais, mas também pelas suas nuanças sócio-econômicas, mostrando-se em sua diversidade, pluralidade, heterogeneidade, flexibilidade, instabilidade e fragmentação. Destacando-se que estes mesmos elementos são justamente os traços que vem delineando a tendência pós-moderna.

De acordo com Vaitsman ${ }^{36}$, as separações e os novos casamentos vêm aumentando o número de pessoas que vivem com parceiros que não são os pais ou as mães de seus próprios filhos. Concomitantemente, aumenta o número de crianças que convivem com seus irmãos, meio-irmãos e "Os filhos do marido/esposa de minha mãe/meu pai». Vêm conquistando seu espaço, os casais de homossexuais, "as pessoas que vivem sós, livres do estigma de solteirões, as mães solteiras e os descasados de ambos os sexos que, juntamente com o exercício simultâneo de alguma atividade remunerada, assumiram a criação dos filhos sem a presença de um parceiro". Além disto, tem-se os filhos, muitas vezes ainda adolescentes, ou mesmo, crianças, como provedores econômicos da família. Vários aspectos ainda passam a compor esta constelação familial, onde mais elementos, por serem o outro significativo, também passam a constituir o espaço familial, como um vizinho, um colega de pensão ou de trabalho, ou mesmo, os teleamigos e os animais de estimação, por exemplo.

O estereótipo familiar da família composta de um marido que é primariamente o provedor e uma 
esposa que fica em casa com suas crianças constitui menor percentual das famílias. Mulheres estão trabalhando fora do lar em números recordes, pessoas são escolhidas através de agências telefônicas de casamento, famílias estão crescendo menores, e tem havido um número crescente de famílias de um único pai, mais freqüentemente encabeçadas por mulheres. ${ }^{37}$

Isto não quer dizer que o padrão da família conjugal predominante na modernidade tenha desaparecido, nem no Brasil, nem em outras partes do mundo. Como chama nossa atenção $V_{a i t s m a n}^{38}$, é preciso enfatizar que não se trata da substituição de um tipo de família, "a conjugal moderna», por outro tipo, a pós-moderna, uma vez que a família hierárquica, marcada pela dicotomia de papéis, não desapareceu. «De maneira mais precisa, o que caracteriza a família e o casamento numa situação pós-moderna é justamente a inexistência de um modelo dominante, seja no que diz respeito às práticas, seja enquanto um discurso normatizador das práticas».

Uma efervescência torna-se evidente neste outro jeito de ser família, deixando-nos mais livres para afirmá-la também como uma tribo, tomando-se a concepção maffesoliana ${ }^{39}$ do termo, dentro de uma perspectiva proxêmica. Assim, tendo uma rede de comunicação que the é peculiar, apresenta necessidade de rituais e enfatiza aquilo que está próximo. Isto porque as famílias vêm se constituindo em função de uma ética específica. Busca uma vida quotidiana mais hedonista, menos determinada pelo «dever-ser», sendo mobilizadas em profundidade pelo não-racional. É possível observar um sentimento de pertença que, todavia, não é absoluto, estabelecendo assim também uma instabilidade, podendo, portanto, ser efêmero. Deste modo, aquele denominado «borboleteamento» que é peculiar a estes outros tempos, também se manifesta na família.

Realçando a ética da estética, uma das tonalidades da pós-modernidade, pode-se ilustrá-la com o que Vaistman ${ }^{40}$ nos traz, ao dizer que a «manutenção da família subordinou-se ao emocional, princípio que passou a orientar comportamentos e estimular as pessoas a recusar relações íntimas sentidas como insatisfatórias".

Tudo isto nos reporta à família na sua unicidade, e não na sua unidade, como já colocado em outros momentos. Isto porque a unidade nos traz a idéia de uniformidade, ou seja, de formas autoritárias e totalizantes de atuar no mundo. ${ }^{41}$ Enquanto que a unicidade, como diz Maffesoli ${ }^{42}$, pressupõe uma união em pontilhado, ou seja, a família se mostra num constante intercâmbio, com outras tribos inclusive, e, sendo assim, também expressando a ambigüidade que o afeto traz consigo: de amabilidade e agressividade; querer estar junto e afastar-se; amar-se e odiar-se; sendo que «tudo isso não ocorre sem dilaceramentos e conflitos de toda ordem".

Alguns poderiam dizer: "mas estas famílias na pós-modernidade são um caos!!! Lembrando Silva ${ }^{43}$, pode-se dizer que «a pós-modernidade afasta-se da servidão e envolve os homens através dos recursos da paixão. Em vez da obrigação da solidariedade mecânica; o bem-estar da comunhão, traduzida na solidariedade orgânica e na socialidade. Em substituição à frieza da norma, o calor da exaltação. Deste modo, muitas famílias não pensam mais em convenções, mas sim em ser feliz.

Este aspecto deve ser sublinhado pelos profissionais da saúde em particular, pois, trabalhando com famílias, buscando promover sua saúde, percebe-se que este ser saudável, passa por uma melhoria de sua qualidade de vida, fundindo-se, cada vez mais, a busca de ser saudável com a busca de ser feliz. Busca que vem sendo bastante discutida em trabalhos recentes dentro da área da saúde, como por exemplo, o de Patrício ${ }^{44}$. Dentro desta discussão, parece oportuno colocação da idéia de Rezende ${ }^{45}$, enfatizando que «a qualidade de vida, neste novo tempo, exige mais do que a sobrevivência finalizada num futuro promissor. Passa, pensamos nós, pelo prazer e pelo júbilo do presente, ...Se antes era preciso ser saudável para o exercício produtivista, na pós-modernidade, mais do que ser saudável, é preciso ser feliz, mesmo que esta felicidade faça perigar a sanidade».

A socialidade pós-moderna, de acordo com Maffesoli ${ }^{46}$, é transfigurada pelas imagens, entendendo-se por transfiguração a passagem de uma figura a uma outra. Assim, para o autor, a "sociedade da imagem" é a marca da pós-modernidade.

Vivemos num "emaranhado cada vez mais complexo de objetos, de signos, de imagens, entre sonho e realidade, prisioneiros sem cadeia de um universo simbólico de significações misteriosas", remetendo a um conjunto entendido enquanto mundo imaginal. Isto tudo coloca em relevo todo um mundo imaginal, no qual as famílias estão imersas. 
Maffesoli ${ }^{47}$, a o tratar o mundo imaginal, foca seu olhar na questão da imagem devido à sua importância contemporânea. Para ele a imagem é cultura e faz cultura. A imagem determina os comportamentos humanos em função de um dado meio e, ao mesmo tempo, ela faz este meio em função destes comportamentos. A imagem é um concentrado do mundo: um tempo e uma história que se espacializam. "Não há qualquer aspecto da vida social que não seja 'contaminado' pela imagem". Ela é um vetor de comunhão com os outros; é um fenômeno que não pretende o absoluto; ela coloca em relação. Este relativismo é que não permite a segurança dogmática de uma razão abstrata. Ela constata uma ligação vital, uma estética emocional em todos os seu afetos.

A imagem, a aparência, não tem uma finalidade precisa ou uma "racionalidade instrumental", exprimindo uma "hiperracionalidade", feita de sonho, de lúdico, de fantasmas, e que parece mais pertinente para descrever o real, ou mesmo, o "hiperreal" que movimenta a vida social. É isto que podemos chamar de mundo imaginal que é como uma matriz na qual todos os elementos de um dado mundano entram em interação, correspondendo-se de maneiras múltiplas e em uma reversibilidade constante. É desta maneira, segundo Maffesoli, que "se pode dizer que o mundo imaginal, de uma maneira realista, leva a sério cada um de seus elementos, não importando qual, e vai deste modo, constituir o real contemporâneo ou pós-moderno.

A partir dessas colocações é que vemos justificada a importância de buscarmos o mundo imaginal se quisermos melhor compreender as famílias contemporâneas. A questão da força da imagem neste dias é ilustrada por Maffesoli e também outros autores, como Baudrillard ${ }^{48}$ e Durand ${ }^{49}, E c O^{50}$, Lyndsay ${ }^{51}$, Soggard, Fonebo ${ }^{52}$ e Rezende ${ }^{53}$, quando trazem sua veiculação através da mídia, mais precisamente a televisão.

$\mathrm{Na}$ área de estudos sobre famílias, já podemos identificar a relevância de tal aspecto quando vemos abrir um amplo debate sobre a questão da televisão nas interações familiares, como ocorreu no III Conferência Ibero-Americana sobre Família ${ }^{54}$, realizada no Brasil, em 1995. Não só houve uma mesa-redonda para o debate específico, como víamos emergir em todos os outros temas esta questão, havendo até quem afirmasse que ela é um novo membro da família, reforçando toda a potência da imagem, numa época em que vivemos a tecnosocialidade.

Voltando-se para a saúde especificamente também percebe-se a relevância de se penetrar o mundo imaginal se quisermos apreender o processo de viver e ser saudável das famílias. Cada um tem o seu mundo imaginal, que é compartilhado, mas não é o mesmo do outro. Assim como o que é ser saudável para cada família e cada profissional é diferente.

Acredita-se que a imagem de ser família saudável e de saúde que as famílias desenvolveram ao longo de sua história vem sendo construída a partir de suas interações, de sua comunhão com os outros, envolvendo toda a sua rede de relações, da mesma maneira que seus comportamentos de saúde também são fundamentados nesta imagem. É pertinente lembrar relatividade desta imagem de ser saudável, quando vemos que a noção de ser saudável e de saúde passa, cada vez mais, por um estado de espírito ${ }^{55}$, pelo sentir-se bem, pelo bem-viver, pelo bem estar, e mesmo pelo serfeliz, como destacamos a pouco. Deste modo, busquemos a real deste sentir-se bem, do bem-viver, do bem estar, e do serfeliz, que emerge de cada um, de cada família, de seu mundo de crenças e de valores, de suas fantasias, suas imaginações, seus símbolos, de seus sonhos, de sua realidade.... Ou melhor, busquemos o "hiperreal"...

Feito este resgate contextual, já colocado em outros trabalhos (Nitschke, 1999), vê-se que é no seio da Pós-modernidade que vemos nutrido o papel da pós-graduação, já que esta se mostra como o meio indicado para acolher controvérsias, integrando diversidades, como as diferentes linhas teóricas, as heterogêneas reflexões filosóficas, a pluralidade ética (afinal vivemos tempos de supermercado ético!), e, sobretudo, a multiplicidade de ser família nos dias de hoje.

\section{BUSCANDO RESPOSTAS E DESCOBRINDO CAMINHOS}

A segunda dimensão do compromisso ético destacada seria o de buscar respostas aos problemas e desejos, ou seja, criar, desenvolver e organizar saberes e tecnologias para promover a melhoria da qualidade de vida e saúde das pessoas, dos grupos, das instituições, 
da nação e do mundo, aponta-nos para reforçar o compromisso ético da Pós-graduação como espaço para construção do conhecimento sobre saúde familial.

Neste sentido, podemos citar os trabalhos liderados por Elsen, a partir de sua tese de doutorado, em 1984, e de um grupo de enfermeiras que desenvolveu sua dissertação dentro do Curso de Mestrado em Enfermagem da UFSC, na área da família, também definindo em seus trabalhos a saúde da família e/ou família saudável, segundo diferentes perspectivas.

Boehs (1990), dentro da linha transcultural e também utilizando a Teoria do Desenvolvimento, considerou como família sadia aquela que mantém um conjunto de reservas físicas, psíquicas, sócioculturais e de ambiente físico que permitem normatizar sua vida e instituir novas normas em situações novas (como o nascimento de um novo membro).

Também seguindo a linha transcultural, Patrício (1990) definiu saúde da família como a capacidade da família de buscar e de normatizar seu bem viver, fundamentada na prática do cuidado, a partir dos recursos de cada membro e da família como unidade, com suas crenças, valores e modos de cuidar, envolvendo as utilização de cuidados do sistema profissional de saúde, incluindo o cuidado de enfermagem.

Em outro momento, Nitschke (1991), colocou-se que a família está saudável quando "houver uma interação positiva caracterizada por um relacionamento direto; de respeito; liberdade e sem tensões; no qual os membros tentam se colocar um no lugar do outro e expressam sentimentos de afeto, idéias, crenças, valores e conceitos, possibilitando-os a crescerem, desenvolverem-se, definirem, ajustarem e desempenharem seus papéis".

Ainda nesta linha, Ribeiro (1990), ao desenvolver seu trabalho junto à famílias maltratadoras, refere-se à saúde familial como uma interação de aproximação entre os membros da família, os quais interagem entre si e com a sociedade.

Para o GAPEFAM (Grupo de Assistência, Pesquisa e Educação na Área da Saúde da Família) família saudável é entendida como "uma unidade que se auto-estima positivamente, onde os membros convivem e se percebem mutuamente como família. Tem uma estrutura e organização para definir objetivos e prover os meios para o crescimento, desenvolvimento, saúde e bem-estar de seus membros. A família saudável se une por laços de afetividade exteriorizados por amor e carinho. Tem liberdade de expor sentimentos e duvidas, compartilha crenças, valores e conhecimentos. Aceita a individualidade de seus membros, possui capacidade de conhecer e usufruir de seus direitos, enfrenta crises, conflitos e contradições, pedindo e dando apoio a seus membros e as pessoas significativas. A família saudável atua conscientemente no ambiente em que vive, interagindo dinamicamente com outras pessoas e famílias em diversos níveis de aproximação, transformando e sendo transformada. Desenvolve-se com experiência, construindo sua história de vida" (Custódio; Henckemaier; Canali, 1992)

Junto com Morais, Pfeiffer (1995), buscamos chamar a atenção para o que é família saudável, identificando alguns conceitos já desenvolvidos na área e sua aplicação a partir de diferentes autores, fazendo uma breve análise. Destacou-se a importância de se explicitar o que é família saudável, emergindo da prática e das crenças e valores das enfermeiras, recomendando que novas investigações fossem desenvolvidas, inclusive à luz das próprias famílias quanto ao seu ser saudável, captando assim a sua realidade.

Cabe ressaltar o aspecto "estado de espírito", já abordado por Elsen (1984), visto que vem carregado de subjetividade, mostrando-nos bem a importância de conhecer o seu mundo imaginal, buscando sua compreensão, pois o estar bem e o estar feliz, enfim o ser saudável tem um significado diferente para cada um, como os trabalhos de Nascimento (1993) e Penna (1996) vêm reforçar. Nos desenhos de algumas crianças do Monte Cristo que, vale lembrar são também imagens, "quando com saúde, se representam sorrindo, dizendo estar alegres e felizes". (Elsen; Hense; Eckert, 1992, p. 28.).

Pode-se perceber a saturação sim dos valores da modernidade, mas não se sabe o que está para vir a tomar seu lugar. Conforme Maffesol/ ${ }^{6}$, «estamos numa época provisória: notamos o que não é mais, mas não conhecemos o que está por vir". Entretanto, para apreendermos este momento é preciso saber buscar no substrato sensível os dados sociais. A ciência, assim, se faz neste momento numa aceitação e convivência de uma pluralidade de métodos. Daí o papel da Pós-graduação em 
exercitar este mosaico de métodos, na busca de desenvolver tecnologias próprias para o trabalho com famílias. Assim, é possível criar espaços, como o Laboratório de Estudos Interdisciplinares sobre a Família, organizado pelo Grupo de Pesquisa, Educação na Área da Saúde da Família (GAPEFAM), que se propõe a desenvolver e testar metodologias próprias para se trabalhar com famílias, refletindo as mais diferentes linhas teórico-metodológicas, numa conjunção respeitando a singularidade de cada uma.

É possivel perceber que a pós-modernidade não represente uma ruptura com a modernidade, ou mesmo com a pré-modernidade. Ela integra. Talvez seja por isto que os estudiosos ao defender uma ou outra, acabam por mesclá-las, definindo uma a partir da outra e muitas vezes, conceituandoas do mesmo modo. Na verdade, este movimento que vivenciamos, não ocorreu de um momento para o outro, ele vem processualmente acontecendo há muito tempo. Tempo este que é cíclico, ou seja, lembrando a espiral, como refere Maffesolp ${ }^{77}$, a história se faz em ciclos, "há um retorno que, no entanto integra mudanças, os desenvolvimentos, as novidades, ou seja, um retorno com 'algo mais',...há qualquer coisa já vista, já conhecida.»

Akoun $^{58}$ coloca que «não podemos resumir a modernidade,...». Assim como não podemos resumir a pós-modernidade. Sem dúvida, é preciso relativizar.

\section{PLURAIS SABERES NA COMPREENSÃO DA SAÚDE FAMILIAL}

A terceira dimensão ressaltada é o de oferecer oportunidades para o desenvolvimento integral do ser humano, comprometido consigo próprio e com a comunidade.

Segundo Leonardo Boff, não somente o homem "se constrói numa lógica complexa, mas também o próprio universo... É a teia de relações pelas quais tudo tem a ver com tudo em todos os momentos e em todas as circunstâncias. É o funcionamento articulado de sistemas e subsistemas que tudo e a todos englobam" (1998, p. 18). Outros autores reforçam estes aspectos, como Michel Maffesoli, Edgar Morin, Fritjof Capra, e Leonardo Boff, quando discutem a simplicidade-complexidade de nosso mundo. A pós-modernidade tem reforçado cada vez mais um trabalho interdisciplinar, devido à conjunção que lhe é peculiar.

Refletindo sobre tal situação, percebe-se a conjunção, a complementaridade, a interdependência deste mundo, ao mesmo tempo simples e complexo, que se mostra a partir das suas interações, e como tal no ser família, e ao se trabalhar com saúde da família.

Pode-se talvez ousar dizer que pressupõe um trabalho transdisciplinar, dentro da visão trazida por Patricio',', isto é, algo que vai além das disciplinas, sem desprezá-las ao mesmo tempo. Ao contrário, integrando-as e transcendendo-as.

Esta situação também tem feito surgir o profissional híbrido, que vemos dia após dia no momento em que perspectivas holísticas se afirmam. Quando se lançou esta idéia (Nitschke, 1999), referia-se aqueles profissionais que, não contentando-se com sua formação de base, que não thes oferece possibilidades de responder a este mundo de conjunção, buscam outras disciplinas tentando contemplar pelo menos um pouco mais da complexidade na qual está inserido. Deste modo, ilustrando, vemos engenheiros que complementam sua formação, a nível de pós-graduação, com estudos de psicologia; psicólogos e assistentes sociais que procuram integrar seus saberes com a enfermagem; administradores que mergulham na filosofia; médicos e enfermeiros que se voltam para a sociologia e antropologia, entre outros.

Ou seja, o profissional não abandona sua formação de base, mas vai, sucessivamente, integrando outros elementos no seu conhecimento e no seu agir os quais, num primeiro olhar, seriam caracterizados como de outras profissões. Invasão? Não! Integração. Complementaridade, conjunção, pois o conhecimento é amplo e não consegue ser limitado a determinados compartimentos. Entretanto, ao olharmos mais atentamente, vê-se que o trabalho realizado não pode ser incorporado por este ou aquele domínio de conhecimento, mas sim pela complexidade do viver da socialidade, expresso no ser familia.

Tem-se uma situação em que poderíamos nos reportar a Vaistman ${ }^{60}$ para ilustrar, «Para não perder o sentido da história nem o da possibilidade de distintas formas de emancipação, estes 
desenvolvimentos recentes, por pós-modernos que sejam, evocam utopias, como aquela calcada" na visão modernista do paraíso, alcançado com o fim da divisão social do trabalho, quando ninguém mais se dedicará a uma só atividade e poderá plenamente diversificar suas atividades - «caçar pela manhã, pescar à tarde, pastorear ao anoitecer, criticar após o jantar, conforme minha vontade, mas jamais me tornar caçador, pescador, pastor ou crítico".

Isto tudo nos aponta que ao enfocarmos a saúde da família na Pós-graduação, é preciso garantir a interdisciplinaridade, integrando inclusive diferentes profissionais e diferentes especialidades. Isto demanda não só no seu corpo docente, na integração de disciplinas de diferentes áreas, mas na possibilidade de desenvolver cursos destinados a profissionais de diferentes domínios de conhecimento, o mesmo ocorrendo com a formação de grupos de pesquisa. O trabalho e a formação profissional, seja a nível de especialização, residência, mestrado, doutorado, ou pós-doutorado, na área da saúde da família foge do encolher limites para acolher integrações. Trabalhar com Saúde da Família é uma questão de postura, na qual, sobretudo, é preciso aprender a relativizar.

\section{UM GRITO DE ALERTA}

Dentro do que entendemos por compromisso ético, a partir de Caponi et al. (1995), para que uma boa existência possa ser construída é preciso que possamos assumir um compromisso inevitável: o de tratar as pessoas como pessoas e nunca como coisas; da mesma forma, tratar as coisas como coisas e nunca como pessoas. Por isso, é preciso relativizar o próprio interesse, ter condições de adotar o ponto de vista do outro. Este é o único compromisso ético ao qual não podemos nos privar. Dito "Kantianamente", poderíamos afirmar que as pessoas nunca podem ser envolvidas como um meio para se conquistar outros fins, mas somente como fins em si mesmo. Isto porque só as pessoas tem um valor absoluto, não condicionado.

Todavia, se não aceitarmos este compromisso e, ao contrário, decidirmos tratar as pessoas como coisas, isto é, como meios para conseguirmos certos fins, então nossas ações serão instrumentais ou estratégicas, mas não éticas. Este compromisso ético, por excelência, de tratar as pessoas como pessoas implica que deveremos reduzir, o máximo possível, o âmbito das ações estratégicas nas quais, através do engano, se manipula os seres humanos, submetendo-os a fins que não são por eles escolhidos.

Deveremos analisar criticamente estes espaços nos quais, os outros e nós, podemos nos converter em objetos de manipulação. Da mesma forma, será preciso ampliar os espaços de autonomia e liberdade aonde cada um, considerado como um fim em si, possa ingressar no âmbito de uma racionalidade comunicativa.

As dificuldades se apresentam neste preciso momento em que nos defrontamos com situações concretas nas quais é evidente qual é o melhor modo de atuar e qual é a ação que de forma mais efetiva nos permitirá a concessão deste compromisso ético.

Deste modo, precisamos estar atentos para as ações que são propostas, refletindo toda uma base teórico-filosófica, e as ações que são efetivamente desenvolvidas. Ao envolver a Saúde da Família, numa proposta de redirecionamento do modelo assistencial, faz-se necessário, portanto, estarmos atentos para que não seja apenas um nome, ou uma maquiagem que reflita uma tendência, mas uma genuína atitude. Neste sentido, a Pós-Graduação desenvolve o papel instrumentalizador para uma avaliação crítica do que vem sendo proposto e do que efetivamente vem sendo realizado. Vale dizer, os cidadãos tem o direito de serem cuidados numa perspectiva que os inclua em suas relações, tanto intra quanto extra-familiais, sendo considerados no seu ambiente, envolvendo sua comunidade, sua nação e, mesmo, o seu planeta.

Vivemos um tempo em que a expressão social tem se apresentado pela heterogeneidade, pluralidade, relatividade, nuanças do que alguns têm chamado de pós-modernidade, um tempo de conjunção, de complementaridade. Assim, não precisamos excluir, mais saúde do indivíduo, a saúde da família, a saúde comunitária, ou privilegiar apenas uma. O ser humano acolhe todas estas dimensões no seu ser saudável, para poder ser acolhido na sua própria humanidade. Quando sublinhamos o ser humano, a demanda de integração é um movimento incessante, mesmo sendo harmonia conflitual.

Deste modo, enfocar saúde da família é colocar foco na melhoria da qualidade de vida dos seres 
Saúde da Família na Pós-Graduação...

humanos com os quais interagimos a o cuidar. Mas como podemos fazer tal afirmação?

Apesar de alguns autores se voltarem exclusivamente para dentro da família para falar de saúde da família e família saudável, a prática tem nos mostrado que trabalhar com família é estar em trânsito entre o micro e o macrosocial, entre o ser humano na sua individualidade e na sua coletividade, enfim é mergulhar infinitamente nas relações intra e extra-familiais. É aprender a relativizar! E a Pós-Graduação precisa garantir isto!

\section{NOTAS}

${ }^{3}$ De acordo com o trazido por Nitschke(1991)," ainda que as palavras familial e familiar sejam sinônimas, conforme Fernandes(1967), o termo familial é eleito por mim numa tentativa de limitá-lo ao que se refere propriamente à família, buscando distinguir do termo familiar que é muito utilizado popularmente também para designar aquilo que "é muito conhecido", "acostumado"

${ }^{4}$ Em sentido mais abrangente, a saúde é a resultante das condições de alimentação, habitação, educação, renda, meio ambiente, trabalho, transporte, emprego, lazer, liberdade, acesso à posse de terra e acesso a serviços de saúde. E, assim, antes de tudo, o resultado de formas de organização social de produção, as quais podem gerar desigualdades nos níveis de vida.

${ }_{5}^{5}$ NASCIMENTO, Paulo César. Democracia e saúde: uma perspectiva arendtiana. In: FLEURY, Sônia. (Org) Saúde coletiva para todos? questionando a onipotência do social. Rio: Relume - Dumara. p. 189.

${ }^{6}$ PENNA, C. M. M. O ser saudável no quotidiano das favelas. Florianópolis: UFSC, 1996. 151 p. Tese (Doutorado em Filosofia da Enfermagem) - Universidade Federal de Santa Catarina, 1996. p. 56.

7 FERNANDES, Francisco. Dicionário brasileiro contemporâneo. 2. ed. Porto Alegre: Globo, 1967. p. 930.

${ }^{8}$ PENNA, C. M. M. O ser saudável no quotidiano das favelas. Florianópolis: UFSC, 1996.151 p. Tese (Doutorado em Filosofia da Enfermagem) - Universidade Federal de Santa Catarina, 1996. p 126

9 PENNA, C. M. M. O ser saudável no quotidiano das favelas. Florianópolis: UFSC, 1996. 151 p. Tese (Doutorado em Filosofia da Enfermagem) - Universidade Federal de Santa Catarina. 1996. p 126

${ }^{10}$ HARTMAN. S. Preparing modern nurse for postmodern families. Holistic Nursing Practice, vol. 9, n.4, July 1995. p. 1

${ }^{11}$ LYOTARD, J.F. La condition postmoderne. Paris: Les Editions de Minuit. 1979. 109 p.

${ }^{12}$ VATIMO, G. La fin de la modernité: nihilismo et herméneutique dans la culture post-moderne. Paris: Éditions du Seuil, 1985. $187 \mathrm{p}$.

${ }^{13}$ COELHO, T. Moderno pós-moderno. 2 ed. Porto Alegre: L \& PM Editores.1986. 175 p.

${ }^{14}$ ROUANET, S. P. \& MAFFESOLI, M. Moderno x pós-moderno. Rio de Janeiro:UERJ, Departamento Cultural, 1994. p.21.

${ }^{15}$ SANTOS, B.S. Pela mão de Alice: o social e o político na pós-modernidade. São Paulo: Cortez, 1995. p. 77. ${ }^{16}$ WATIER, P. op cit,

${ }^{17}$ VAISTMAN, Jeni. Flexíveis e plurais: casamento e família em circunstâncias pós-modernas, Rio de Janeiro: Rocco, 1994. 203 p.

${ }^{18}$ ROUANET, S. P. \& MAFFESOLI, M. op cit.

${ }^{19}$ SILVA, Juremir Machado da. Anjos da perdição: futuro e presente na cultura brasileira. Porto Alegre: Sulina, 1996. p.24-27; 246

${ }^{20} \mathrm{~A}$ socialidade, segundo Maffesoli, é a potência social que tenta se exprimir, residindo num misto de sentimentos, paixão, imagens, diferenças que incitam a relativizar as certezas estabelecidas a uma multiplicidade de experiências coletivas . O autor, invertendo os termos propostos por Durkheim, propõe a solidariedade orgânica como aquela que é calcada em laços sociais afetivos e nas ambigüidade básica da estruturação simbólica, garantindo a coesão do grupo, a partilha sentimental de valores, lugares e idéias, enquanto a solidariedade mecânica, seria da ordem do instituído. MAFFESOLI, M. A conquista do presente. Rio de Janeiro: Rocco, 1984. e MAFFESOLI, M. O conhecimento do quotidiano. Lisboa: Vega. s/d. p.173.

${ }^{21}$ SILVA, Juremir Machado da. Op. cit.

${ }^{22}$ HARTMAN. S. op. cit. p. 1 - 10.

${ }^{23}$ HARTMAN. S. op cit.

${ }^{24}$ GERGEN, K.J, apud op. cit.

${ }^{25}$ MAFFESOLI, Michel. A tecnosocialidade como fator de laço social. Palestra no Curso de Pós-Graduação em Jornalismo da PUC- Porto Alegre - RS, em 16 de outubro de 1996.

${ }^{26}$ SILVA, Juremir Machado da. op cit.

${ }^{27}$ SILVA, Juremir Machado da. op cit. 
${ }^{28}$ ROUANET, S. P. \& MAFFESOLI, $M$ op cit. p.21.

${ }^{29}$ MAFFESOLI, M. Aux creux des apparences: pour une éthique de l'esthétique. Paris: Plon, 1990. p.55.

${ }^{30}$ ROUANET, S. P. \& MAFFESOLI, M. op cit. p.81.

${ }^{31}$ SILVA, Juremir Machado da. op cit.

32 BARRETO, A. Família, loucura e cultura. Revista Família (Centro de Estudos da Família), Fortaleza, ano 2 , n.1, p. 61-70, 1987

${ }^{33}$ SILVA, Juremir Machado da. op cit.

${ }^{34}$ VAISTMAN, Jeni. F. op cit. p.13 - 24.

${ }^{35}$ KALOUSTIAN, S. M. Família brasileira: a base de tudo. São Paulo: Cortez; Brasília: UNICEF, 1994.

${ }^{36}$ VAISTMAN, Jeni. Op cit. p.13- 24

${ }^{37}$ HARTMAN. S. op cit. p. 1 - 10

${ }^{38}$ VAISTMAN, Jeni. Op cit. p.13 - 24.

${ }^{39}$ MAFFESOLI, M. O tempo das tribos: o declínio do individualismo nas sociedades de massa. Rio de Janeiro: Forense, 1987. p 197.

${ }^{40}$ VAISTMAN, Jeni. Op cit. p.14.

${ }^{41}$ REZENDE, A.L. M. Pós-modernidade: o vitalismo no "chaos". Florianópolis.1993. Plural, v.3, n.4., jan-jul., p. 10

${ }^{42}$ MAFFESOLI, M. op cit. p.176.

${ }^{43}$ SILVA, Juremir Machado da. op cit.

${ }^{44}$ PATRÍCIO, Z.M. op cit.

${ }^{45}$ REZENDE, A.L.M. op. cit. p.12.

${ }^{46}$ MAFFESOLI, M. La contemplation du monde. Paris: Grasset. 1993, p. 187.

${ }^{47}$ MAFFESOLI, M. op cit. p. 187.

${ }^{48}$ BAUDRILLARD, J. Da sedução, 2. ed. Campinas: Papirus, 1992, p.186.

49 DURAND, G. L'imaginaire. Paris: Hatier, 1994. p. 77-79.

${ }^{50} \mathrm{ECO}, \mathrm{U}$. Apocalípticos e integrados. São Paulo: Perspectiva, 1979.

${ }^{51}$ LINDSAY, B. Influencing development: the media. In: LINDSAY, B. The child and the family. London: Baillière Tindall, 1994.

52 SOGGARD, A. J.; FONNEBO, V. Self-reported change in health behavior after a mass media-based health education campaign. Journal's Psychologie, v. 33, n. 2, p.125-134, 1992.

${ }^{53}$ REZENDE, A.L.M. de. A sedução dos mitos de saúde/doença na telenovela. São Paulo: USP, 1991. Tese (Doutorado) - Faculdade de Educação USP.

54 III Conferência Ibero-Americana sobre Família, São Leopoldo, UNISINOS, 1995, 24p. (Programa )

${ }^{55}$ ELSEN, I. Concepts of health and illness and related behaviors among families living in a Brasilian fishing village. San Francisco: University of California, 1984. Tese (Doutorado em Ciência da Enfermagem) University of California, 1984.

${ }^{56}$ ROUANET, S. P. \& MAFFESOLI, M. op cit, p.22

${ }^{57}$ ROUANET, S. P. \& MAFFESOLI, M. op cit. p. 20.

${ }^{58}$ AKOUN, A. op cit.

${ }^{59}$ PATRíCIO, Z.M. A dimensão felicidade-prazer no processo de viver saudável individual e coletivo: uma questão bioética numa abordagem holístico-écológica. Florianópolis: UFSC, 1995. 215 p. Tese (Doutorado em Filosofia da Enfermagem) - Universidade Federal de Santa Catarina, 1995. p. 38.

${ }^{60}$ VAISTMAN, Jeni. Op cit, p.14.

\section{REFERÊNCIAS BIBLIOGRÁFICAS}

AKOUN, A. Modernité et pós-modernité. Societés: revue des sciences humaines et sociales, Montrouge Cedex, n. 48, p.147-149, 1995.

BACH, R. Ilusões: as aventuras de um messias indeciso. 18. ed . Rio de Janeiro: Record. [199-] p. 71.

BARRETO, A. Família, loucura e cultura. Revista Família, Fortaleza, v. 2, n.1, p. 61-70, 1987.

BAUDRILLARD, J. Da sedução. 2. ed., Campinas: Papirus, 1992, p.186. 
BOMAR, P. J. Perspectives on family health promotion. Family Community Health, v. 12, n. 4, p. 1-11, 1990.

CAPONI, Sandra; ELSEN, Ingrid; NITSCHKE, Rosane G. Projetos de apoio à convivência familiar e comunitária: um compromisso ético da universidade. In: CONFERÊNCIA IBERO-AMERICANA SOBRE FAMÍLIA, 3., São Leopoldo, UNISINOS, 1995. 24p. (em fase de publicação)

COELHO, T. Moderno pós-moderno. 2. ed. Porto Alegre: L \& PM Editores, 1986. 175 p.

DURAND, G. L'imaginaire. Paris: Hatier, 1994. p. 77-79.

ECO, U. Apocalípticos e integrados. São Paulo: Perspectiva, 1979.

ELSEN, I. Concepts of health and illness and related behaviors among families living in a Brasilian fishing village. San Francisco: University of California, 1984. Tese (Doutorado em Ciência da Enfermagem), University of California, 1984.

ELSEN, Ingrid. Saúde familiar: a trajetória de um grupo. In: ELSEN, Ingrid; BUB, Lidia Ignes Rossi; PENNA, Cláudia Maria; ALTHOFF, Coleta Rinaldi; PATRíCIO, Zuleica Maria (Org) Marcos para a prática de enfermagem com famílias. Florianópolis: Editora da UFSC, 1994. 195p. p. 19-60.

ELSEN, Ingrid; NITSCHKE, Rosane G. Pós-graduação, pesquisa e ética: um tema acima de qualquer questionamento? Texto \&Contexto-Enf., Florianópolis, v. 3, n. 1, p. 7-19, jan. / jun. 1994. p. 9.

FERNANDES, Francisco. Dicionário brasileiro contemporâneo. 2.ed. Porto Alegre: Globo, 1967. $1143 p$.

GILLIS, C. L. et al. What is family nursing? In: GILLIS, C. L. et al. Toward a science of family nursing. California: Addson-Wesley, 1989. p. 79. e GILLIS, C. L. Why family health care? In: GILLIS, C. L. et al. Toward a science of family nursing. California: Addson-Wesley, 1989. p. 3-7.

GULLO, C. \& BRISSAC, C. Famílias coloridas. Revista Isto É, São Paulo, 21 de agosto de 1996. p.52 - 54.

HARTMAN. S. Preparing modern nurse for postmodern families. Holistic Nursing Practice, vol. 9, n.4, p.1, July, 1995.

KALOUSTIAN, S. M. Familia brasileira: a base de tudo. São Paulo: Cortez; Brasília: UNICEF, 1994.

LINDSAY, B. Influencing development: the media. In: LINDSAY, B. The child and the family. London: Baillière Tindall, 1994.

LYOTARD, J.F. La condition postmoderne. Paris: Les Editions de Minuit, 1979. 109 p.

MAFFESOLI, M. A conquista do presente. Rio de Janeiro: Rocco, 1984.

O tempo das tribos: o declínio do individualismo nas sociedades de massa. Rio de Janeiro: Forense, 1987. p 197.

Aux creux des apparences: pour une éthique de l'esthétique. Paris: Plon, 1990. p.55.

La contemplation du monde. Paris: Grasset, 1993.

A tecnosocialidade como fator de laço social. Palestra no Curso de Pós-Graduação em Jornalismo da PUC - Porto Alegre - RS, em 16 de outubro de 1996.

O conhecimento do quotidiano. Lisboa: Vega, s/d. p.117.

MINISTÉRIO DA SAÚDE, Sáude da família: uma estratégia para reorientação do modelo assistencial. Brasília. Ministério da Saúde, 1998. 36 p. 
NITSCHKE, Rosane Gonçalves. Nascer em família: uma proposta de assistência de enfermagem para a interação familial saudável. Florianópolis: UFSC, 1991, 313p. Dissertação (Mestrado em Enfermagem) Universidade Federal de Santa Catarina, 1991.

Uma viagem pelo mundo imaginal de ser família saudável no quotidiano em tempos pós-modernos: a descoberta dos laços de afeto como caminho. Florianópolis: UFSC, 1999, 462p. Tese (Doutorado em Filosofia da Enfermagem) Universidade Federal de Santa Catarina, 1999.

Mundo imaginal de ser família saudável: a descoberta dos laços de afeto como caminho numa viagem pelo no quotidiano em tempos pós-modernos. Pelotas: Universitária/ UFPel, 1999. 199 p.

PATRÍCIO, Z.M. A dimensão felicidade-prazer no processo de viver saudável individual e coletivo: uma questão bioética numa abordagem holístico-écológica. Florianópolis: UFSC, 1995. 215 p. Tese (Doutorado em Filosofia da Enfermagem) - Universidade Federal de Santa Catarina, 1995. p. 38.

QUINTANA. M. Prosa e verso. 6. ed. São Paulo: Globo.1989. p. 120.

REZENDE, A.L.M. de. A sedução dos mitos de saúde/doença na telenovela. São Paulo: Faculdade de Educação, USP, 1991. Tese (Doutorado em Educação) - Faculdade de Educação, USP, 1991.

REZENDE, A.L. M. Pós-modernidade: o vitalismo no "chaos". Florianópolis. Plural, v.3, n.4., p.10, jan-jul. 1993.

SANTOS, B.S. Pela mão de Alice: o social e o político na pós-modernidade. São Paulo: Cortez, 1995. p. 77.

SAVATER, F. El contenido de la felicidad. Aguilar: Madrid, 1994.

SILVA, Juremir Machado da. Anjos da perdição: futuro e presente na cultura brasileira. Porto Alegre: Sulina, 1996. p.24-27; 246.

SOGGARD, A. J.; FONNEBO, V. Self-reported change in health behavior after a mass media-based health education campaign. Journal's Psychologie, v. 33, n. 2, p.125-134, 1992.

VAISTMAN, Jeni. Flexíveis e plurais: casamento e família em circunstâncias pós-modernas. Rio de Janeiro: Rocco, 1994. 203 p.

VATIMO, G. La fin de la modernité: nihilismo et herméneutique dans la culture post-moderne. Paris: Éditions du Seuil, 1985. 187 p.

WATIER, P. Réflexivité institutionnelle, modes de vie et modernité. Societés: revue des sciences humaines et socials, Dunod Ed. Paris - Montrouge Cedex, n.48, p.133 - 145, 1995.

III CONFERÊNCIA IBERO-AMERICANA SOBRE FAMÍLIA, São Leopoldo, UNISINOS, 1995. 24p. (Programa). 